\title{
Palliative intubation for malignant strictures of the oesophagus
}

\author{
J. N. LEVER ME N T a d D. MEAR N S M L N E \\ Frenchay Hospital, Bristol
}

\begin{abstract}
Leverment, J. N. and Mearns Milne, D. (1974). Thorax, 29, 228-231. Palliative intubation for malignant strictures of the oesophagus. Over a 16-year period the Mousseau-Barbin tube was used for palliation in 50 patients suffering from malignant stricture of the oesophagus. In only two cases was the Souttar tube used.

Thirty-seven cases were intubated as a primary method of treatment -21 cases without preliminary exploration, 13 cases following exploration, and three cases as a 'delayed' procedure.

Twelve cases were secondarily intubated as a result of recurrence of malignancy following an earlier oesophagogastrectomy.

In three cases perforation of the oesophagus was recognized at the time of intubation, following which palliative oesophagogastrectomies were attempted.

Intubation remains one method of relieving the patient's most distressing symptom, but in the majority of cases prolongation of life was seldom for more than three months. The hazards of this form of treatment are discussed.
\end{abstract}

Notwithstanding the great strides made in cardiac surgery, the treatment of cancer of the oesophagus remains an unfortunate chapter in cardiothoracic surgery.

In most cases, palliation and a moderate prolongation of life is all that can be achieved by surgical excision; however, the psychological benefit to the patient of being able to swallow and to have the cancer 'removed' is gratifying.

The anatomical position of the oesophagus, by its proximity to important structures, precludes the application of the ideal cancer operation. In most cases diagnosis is late, and spread beyond the wall of the oesophagus and into the connective tissue and neighbouring structures by contiguity, and more distant spread to lymph nodes, has occurred.

Thus a percentage of cases are seen where, owing to spread, the lesion is irresectable, and in a small percentage inoperable, owing to the unsatisfactory state of health of the patient. They, however, still require relief of their most distressing symptom.

Palliation by dilatation has been used by Menguy (1964). Symonds $(1885,1887)$ described relief of dysphagia by permanent catheter and

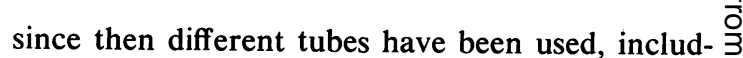
ing those of Souttar (1824), Celestin (1959), Mackler and Mayer (1954), Brown (1949), Berman (1952), Mousseau, Le Forestier, Barbin, and Hardy (1956), and Ammann and Collis (1971).

In this series of patients only two had Souttar tubes inserted and in both cases the tube became displaced into the stomach. All the other patients were intubated with a Mousseau-Barbin tube.

\section{CLINICAL MATERIAL}

From 1954 to 1970, 355 patients were admitted $\frac{7}{0}$ under one thoracic surgical consultant (D.M.M.) with carcinoma of the oesophagus and cardia. In addition $N$ to the 37 patients treated by intubation as a primary method of treatment, 12 required intubation as a secondary measure as a result of recurrent dysphagia $\underset{\omega}{ }$ following previous resection. There were also three patients in whom intubation was attempted but resulted in the creation of a false passage for which $\underset{\mathbb{D}}{\stackrel{C}{D}}$ palliative oesophagogastrectomy was necessary $\mathscr{\Phi}$ (Table I).

\section{'PRIMARY' INTUBATIONS (Table II)}

Patients not explored Decision not to subject 21 patients to major exploratory and resective procedures was made entirely on clinical assessment, electrocardiographic, radiological, and endoscopic findings. 
T A B L E I

ANALYSIS OF PATIENTS TREATED DURING THE PERIOD 1954-70

\begin{tabular}{l|rr}
\hline \multicolumn{1}{c|}{ Details } & No. & \multicolumn{1}{c}{$\%$} \\
\hline Oesophagogastrectomy & 297 & $83 \cdot 7$ \\
Other type of resections & 15 & $4 \cdot 2$ \\
Palliative intubation & 37 & $10 \cdot 4$ \\
Exploratory thoracotomy & 1 & $0 \cdot 3$ \\
Anaesthetic death & 1 & $0 \cdot 3$ \\
No operation & 4 & $1 \cdot 1$ \\
\hline
\end{tabular}

T A B L E I I

'PRIMARY' INTUBATIONS AND SITE OF LESION

\begin{tabular}{l|c|c|c}
\hline & $\begin{array}{c}\text { Not } \\
\text { Explored }\end{array}$ & Explored & Delayed \\
\hline Junction upper and middle thirds & - & 1 & - \\
Middle third & 16 & 3 & 3 \\
Lower half & 1 & 2 & - \\
Lower third & 3 & 2 & - \\
Cardia (stomach) & 1 & 5 & - \\
\hline
\end{tabular}

In only five was the general state of health of the patient unsatisfactory for major resection.

One patient had a left pneumonectomy for primary carcimona of the bronchus six months before the development of dysphagia from a middle third lesion which was endoscopically visible. The patient died 13 hours postoperatively from mediastinitis as a result of a perforation. Necropsy confirmed a new primary in the oesophagus and distortion of the normal anatomy.

In another patient, an elderly schizophrenic, we felt adequate postoperative control and care would have been impossible. This patient was our longest survivor following palliative intubation (11 months) but required oesophagoscopy on two occasions to unblock the tube. Three patients had diffuse bilateral bronchopneumonia with cardiac arrythmias.

The other patients were irresectable owing to extensive local disease with direct spread into the tracheobronchial tree, recurrent nerve, pericardium and major vessels, and/or palpable cervical and abdominal lymph node secondaries and clinical and radiological evidence of haematogenous spread into the lung parenchyma and liver.

Seventy-five per cent of these cases had middle third lesions. Two patients were referred to us by an ENT surgeon who recognized that tumour visible in the vallecula fossa was part of a continuous tumour of the upper oesophagus, the main obstructive growth being situated in the middle third.

Exploratory intubation In 13 patients irresectability was determined only after exploration. This in the main was due to error of judgement in the preoperative assessment. In the latest 159 consecutive cases explored, oesophagogastrectomy was completed in $155(79 \cdot 5 \%)$.

In one case resection of a tumour situated at the junction of the upper and middle thirds of the oesophagus was not accomplished. A Souttar tube was inserted as it was felt that the comfort of the patient would not be assured using the Mousseau-Barbin tube at this level.

Five cases with cardiac lesions involving the lower oesophagus were explored; irresectability could not be determined preoperatively.

Delayed intubation Three patients with extensive, irresectable middle third lesions could still swallow semisolids. Nothing was done apart from endoscopic examination. Two of these patients were readmitted three months later and the third, seven months later, all with worsening of their dysphagia. At this stage intubation was carried out in each case; all died within the next two months.

SECONDARY INTUBATIONS (Table III) Twelve cases $(5.8 \%)$ out of 288 survivors following oesophagogastrectomy returned with their original symptoms, the causes of which are listed in Table III, and the level of the original lesion resected in Table IV. In seven out of the 12 cases the pathology of the original tumour was an adenocarcinoma.

T A B L E I I I

\begin{tabular}{l|l}
\multicolumn{1}{c}{$\begin{array}{c}\text { 'SECONDARY' INTUBATIONS FOR RECURRENT } \\
\text { MALIGNANCY }\end{array}$} \\
\hline Site of Recurrence & No. \\
\hline Anastomosis & 6 \\
Mediastinum & $3^{1}$ \\
Gastric remnant & $2^{2}$ \\
Paraduodenal & 1 \\
\hline
\end{tabular}

${ }^{1}$ One failure to intubate

T A B L E I V

LEVELS OF ORIGINAL LESIONS RESECTED

\begin{tabular}{l|c}
\hline \multicolumn{1}{c|}{ Level } & No. \\
\hline Middle third & 4 \\
Lower half & 3 \\
Lower third and cardia & 3 \\
Stomach & 2 \\
\hline
\end{tabular}

Of the cases who had middle third lesions resected, recurrence was evident in two by endoscopic visualization of tumour tissue at the anastomotic line 10 months and three years after resection, in another case by extrinsic compression of the oesophagus shown on contrast studies, and in another by the presence of a malignant tracheo-oesophageal fistula and palpable liver secondaries.

One patient who presented with duodenal obstruction two years after resection of an adenocarcinoma of the lower third of the oesophagus was found to have secondary involvement of lymph nodes around the head of the pancreas and the hilum of the liver at laparotomy. A Mousseau-Barbin tube was inserted through a small gastrotomy retrogradely into the duodenum. The patient survived for two months. 
In one patient with total dysphagia and a malignant fistula an attempt to pass the prosthesis failed, and in another patient 'early' recurrence was visible endoscopically at the anastomotic line. However, at re-exploration there was extensive mediastinal infiltration, making re-resection impossible.

Of these 12 patients three died in hospital and none survived for more than two months. Furthermore, three returned with blocked tubes even though they had been cautioned before discharge on the degree of palliation achieved by intubation compared with that of their previous resection and instructed on the type and consistency of future food intake.

In three cases death was due to massive haemorrhage from gastric erosion. Necropsy carried out in two cases confirmed that the erosion was opposite the end of the prosthesis.

ATTEMPTED INTUBATIONS FOLLOWED BY OESOPHAGOGASTRECTOMY Three patients had irresectable middlethird lesions and suffered from chronic bronchitis and emphysema. In addition, one of them had severe kyphoscoliosis with chest wall deformity, and another had heart block with auricular flutter secondary to a previous coronary thrombosis.

In each patient attempts to pass a prosthesis resulted in the creation of a false passage, following which palliative oesophagogastrectomy was carried out. The patient with a previous coronary thrombosis arrested following closure of the chest wall; necropsy confirmed a massive myocardial infarction. The other two patients gradually deteriorated postoperatively over a period of two weeks.

\section{DISCUSSION}

The need for early diagnosis must be stressed. The majority of patients had middle third lesions. It is in these that spread at an early stage into surrounding structures makes the lesion irresectable. Three of our cases also demonstrate the futility in attempting to resect these lesions when palliative intubation was originally planned.

Indication for intubation was in the main extensive carcinoma rather than unfitness for prolonged anaesthesia. In most cases the debility and cachexia do not represent irresectability of the lesion, and this fact is reflected in our high resection rate.

Favourable reports have been published on the use of the Mousseau-Barbin tube in malignant disease (Waddington and Bickford, 1962; Barnard, Kilroy, and Kennedy, 1966) but in our experience it has not been entirely satisfactory. The hospital mortality of patients who required intubation as a primary method of treatment was high, and the majority of survivors died within two months (Table V). This cannot be attributed entirely to the extensiveness of their carcinomas because
T A B L E V

RESULTS OF TREATMENT IN PATIENTS WITH 'PRIMARY' TUBES

\begin{tabular}{|c|c|c|}
\hline Time of Death & No. & $\%$ \\
\hline $\begin{array}{l}\text { In hospital } \\
\text { Within } 3 \text { months } \\
3-7 \text { months } \\
9 \text { months } \\
11 \text { months }\end{array}$ & $\begin{array}{r}17 \\
11 \\
7 \\
1 \\
1\end{array}$ & \begin{tabular}{r}
\multicolumn{1}{c}{46} \\
$29 \cdot 7$ \\
$18 \cdot 9$ \\
$2 \cdot 7$ \\
$2 \cdot 7$
\end{tabular} \\
\hline
\end{tabular}

three patients with similarly advanced and irresectable malignancy but not requiring immediate intubation survived considerably longerce without intubation, but died within two months? following intubation.

Dilatation of a malignant stricture remains one $e_{\circ}^{\infty}$ of the most uncontrolled and hazardous pro- cedures in thoracic surgery and becomes more $\vec{z}$ hazardous in situations where there is distortion of the normal anatomy apart from the presence of $\stackrel{5}{5}$ the neoplasm, such as in patients who have had $\vec{\varphi}$ previous thoracic operations or spinal and chest deformities. This procedure should therefore not be done by junior staff without supervision.

The Mousseau-Barbin tube has inherent physical dangers. The flange is too large and re-o quires trimming to prevent erosion of the oeso-0 phagus by pressure necrosis. Also trimming is necessary to prevent obstruction due to buckling $\overrightarrow{0}$ of the rim of the funnel (hour-glass deformity).

Even though we have taken great care when? trimming the distal end of the tube, deaths have? occurred from fatal haemorrhage from gastric erosions. Two deaths occurred from this complica-o tion in our primary intubations, three in patients with previous oesophagogastrectomies (secondaryo intubations) and one following insertion of this tube in an irresectable benign stricture (Raptisô and Mearns Milne, 1972).

When a distensible organ like the oesophagus? becomes indistensible over a certain portion of its length by malignant infiltration, and becomes․ fixed in a confined space while the surrounding structures such as the tracheobronchial tree and ${ }^{\circ}$ aorta, although partly infiltrated, retain some 0 ability to stretch, too aggressive attempts to insert a tube can only result in tears developing in thosed structures which have partly retained theiko elasticity. This is probably the main mechanismo by which tracheobronchial oesophageal fistula and? fatal haemorrhage from the thoracic aorta occur, 0 rather than by direct perforation of these structures.

There is no doubt that palliation was achieved by relieving the patient's most distressing symp tom, that of inability to swallow his own saliva. 
Gradual deterioration due to bilateral bronchopneumonic changes, no doubt from intermittent aspiration, occurred in most of the patients in whom the prostheses were placed near the pharyngo-oesophageal junction, and to a lesser extent with prostheses placed lower. Direct reflux of gastric content up the lumen of the tube doubtless occurred, but we feel that inco-ordination between pharynx, pharyngo-oesophageal sphincter, and upper oesophagus resulted in the finding of food particles in the lungs without the tubes being blocked.

Satisfactory palliation was not achieved in patients with tracheo-oesophageal fistulae. Palliation was measured in days rather than weeks with recurrence of direct spillage of saliva from the oesophagus through the fistula into the tracheobronchial tree.

\section{REFERENCES}

Ammann, J. F. and Collis, J. L. (1971). Palliative intubation of the esophagus. Analysis of 59 cases. Journal of Thoracic and Cardiovascular Surgery, 61, 863.

Barnard, P. M., Kilroy, E. G., and Kennedy, J. H. (1966). Inoperable cancer of the esophagus: use of the Mosseau-Barbin tube in palliative surgery. Journal of Thoracic and Cardiovascular Surgery, 51, 125.

Berman, E. F. (1952). Plastic prosthesis for resected esophagus. Archives of Surgery, 65, 916.

Brown, A. L. (1949). Carcinoma of the esophagus. Use of a rigid indwelling esophageal tube. Journal of Thoracic Surgery, 18, 493.
Celestin, L. R. (1959). Permanent intubation in inoperable cancer of the oesophagus and cardia. A new tube. Annals of the Royal College of Surgeons of England, 25, 165.

Mackler, S. A. and Mayer, R. M. (1954). Palliation of esophageal obstruction due to carcinoma with a permanent intraluminal tube. Journal of Thoracic Surgery, 28, 431.

Menguy, R. (1964). The role of bouginage in the palliative management of esophageal cancer. Surgery, Gynecology and Obstetrics, 119, 849.

Mousseau, M., Le Forestier, J., Barbin, J., and Hardy, M. (1956). The indications for permanent intubation in the palliative treatment of carcinoma of the oesophagus. Archives des Maladies de l'Appareil Digestif et des Maladies de la Nutrition, 45, 208.

Raptis, S. and Mearns Milne, D. (1972). A review of the management of 100 cases of benign stricture of the oesophagus. Thorax, 27, 599.

Souttar, H. S. (1924). A method of intubating the oesophagus for malignant stricture. British Medical Journal, 1, 782 .

Symonds, C. J., (1885). A case of malignant stricture of the oesophagus illustrating the use of a new form of oesophageal catheter. Transactions of the Clinical Society of London, 18, 155.

- (1887). The treatment of malignant stricture of the oesophagus by tubage or permanent catheterism. British Medical Journal, 1, 870.

Waddington, J. K. B. and Bickford, B. J. (1962). The use of the Mousseau-Barbin tube for palliation in carcinoma of the oesophagus and cardia. British Journal of Surgery, 49, 522.

Requests for reprints to: D. Mearns Milne, F.R.C.S., Thoracic Surgical Unit, Frenchay Hospital, Bristol. 